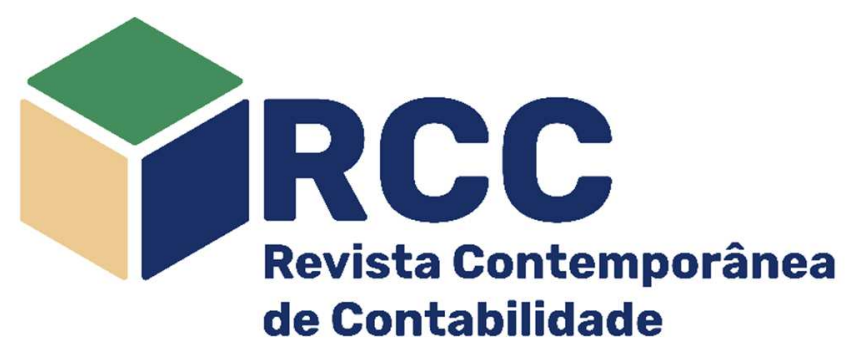

\title{
Impactos da adoção das international financial reporting standards (IFRS) nos indicadores econômico-financeiros de instituições financeiras brasileiras
}

\author{
Effects of adoption of international financial reporting standards (IFRS) in the economic and financial \\ indicators of Brazilian financial institutions
}

Efectos de la adopción de las normas internacionales de información financiera (NIIF) en los indicadores económicos y financieros de las instituciones financieras brasileñas

Thaís de Freitas Daneberg Mestre em Ciências Contábeis (UNISINOS) Professora da Universidade Católica de Pelotas, Pelotas/RS, Brasil tdaneberg@gmail.com https://orcid.org/0000-0001-5512-8165 (])
Roberto Frota Decourt Doutor em Administração (UFRGS) Professor do Programa de Pós-Graduação em Ciências Contábeis (UNISINOS), Porto Alegre/RS, Brasil rfdecourt@unisinos.br https://orcid.org/0000-0002-9419-498X

Endereço do contato principal para correspondência* Av. Palmeira, 725, CEP: 90470-300 - Porto Alegre/RS, Brasil

\section{Resumo}

O objetivo desta pesquisa é avaliar os impactos da adoção das IFRS (IAS 7, IAS 19, IAS 32 e IAS 39) nos indicadores econômico-financeiros de instituições financeiras brasileiras, por meio dos indicadores de solvência, estrutura patrimonial e de captação, e de rentabilidade. O método utilizado foi comparar os resultados referentes ao ano de 2009 e que tiveram suas demonstrações financeiras publicadas de acordo com as normas BR GAAP e IFRS. Foram comparadas as médias de cada um dos indicadores econômicofinanceiros, calculados em ambos os padrões contábeis e para identificar se as diferenças encontradas eram significativas foi aplicado o teste Mann Whitney. Como teste de robustez foram comparadas as proporções de variações positivas e negativas dos indicadores analisados e para identificar se as diferenças eram significativas foi aplicado o teste chi-quadrado. Os resultados encontrados sugerem que o ajuste ao valor recuperável de empréstimos e adiantamentos e o ajuste ao valor justo de ativos financeiros influenciaram para que a carteira de crédito e o patrimônio líquido das instituições financeiras analisadas apresentassem de maneira geral valores maiores quando demonstradas em IFRS, o que elevou os indicadores Independência Financeira; Empréstimos/Depósitos e reduziu os indicadores Alavancagem; Participação dos Empréstimos; Retorno sobre o Patrimônio Líquido. Não foi possível constatar nenhuma diferença significativa, provavelmente devido a pequena amostra trabalhada. Esta pesquisa pretende ter contribuído para aprimorar o entendimento dos impactos do processo de convergência da contabilidade das instituições financeiras brasileiras, que por muitas vezes são excluídas das pesquisas por suas particularidades, para o padrão internacional; bem como, para auxiliar os gestores de negócios e os usuários da informação financeira, especialmente aqueles oriundos do mercado de capitais, as autoridades reguladoras e a academia.

Palavras-chave: IFRS; Indicadores econômico-financeiros; Instituições Financeiras

\section{Abstract}

The objective of this research was to evaluate the impact of adopting IFRS (IAS 7, IAS 19, IAS 32, and IAS 39) on the financial indicators of Brazilian financial institutions, through the solvency indicators, capital structure and funding, and profitability. The method used was to compare the year 2009 when their financial statements were published according to BR GAAP and IFRS. The averages were compared for each of the economic indicators, calculated in both accounting standards, and to identify whether the differences were significant was applied Mann Whitney test. As a robustness test, the proportions of positive and negative variations of 
the analyzed indicators were compared. The chi-square test was applied to identify whether the differences were significant. The results suggest that the adjustment to the impairment of loans and advances and the adjustment to the fair value of financial assets influenced so that the loan portfolio and the equity of the analyzed financial institutions presented in general higher values as stated in IFRS, which raised Financial Independence indicators; Loans / Deposits and reduced leverage indicators; Borrowing participation; Return on Equity. We could not find any significant difference, probably due to the small sample size. This research aims to have contributed to improving the understanding of the impact of the convergence process of the accounting of Brazilian financial institutions, which often are excluded from searches by its peculiarities, to the international standard; as well as to assist business managers and users of financial information, especially those from the capital market, regulatory authorities and academia.

Keywords: IFRS; Financial indicators; Financial Institution

\section{Resumen}

El objetivo de esta investigación fue evaluar el impacto de la adopción de los IFRS (IAS 7, IAS 19, IAS 32 and IAS 39) en los indicadores financieros de las instituciones financieras brasileñas, a través de la estructura de los indicadores de solvencia de capital y financiación, y la rentabilidad. El método utilizado fue el de comparar los resultados para el año 2009, cuando sus estados financieros se publicarán de conformidad con el BR GAAP e IFRS. Las medias se compararon para cada uno de los indicadores financieros, calculada en ambos estándares de contabilidad e identificar si las diferencias fueron significativas, se aplicó la prueba de Mann Whitney. Como prueba de robustez, se compararon las proporciones de variaciones positivas y negativas de los indicadores analizados y para identificar si las diferencias eran significativas se aplicó la prueba de chicuadrado. Los resultados sugieren que el ajuste al deterioro de los préstamos y anticipos y el ajuste al valor razonable de los activos financieros influenciados por lo que la cartera de crédito y el capital de las instituciones financieras analizadas se presentan en valores superiores generales como se indica en IFRS, lo que elevó la independencia financiera indicadores; Préstamos / depósitos y la reducción de los indicadores de apalancamiento; El préstamo de la participación; Rentabilidad sobre recursos propios. No hemos podido encontrar ninguna diferencia significativa, probablemente debido al pequeño tamaño de la muestra. Esta investigación tiene como objetivo han contribuido a mejorar la comprensión de los efectos del proceso de convergencia de la contabilidad de las instituciones financieras brasileñas, que a menudo son excluidos de las búsquedas por sus peculiaridades, a la norma internacional; así como para ayudar a los gerentes de empresas y usuarios de la información financiera, especialmente los del mercado de capitales, las autoridades reguladoras y el mundo académico.

Palabras-clave: NIIF; Indicadores financieros; Institución financiera

\section{Introdução}

A avaliação da situação econômico-financeira das organizações está diretamente relacionada à qualidade da informação e de sua evolução histórica. Diante disso, o usuário que se utilizar destas informações para subsidiar o processo de tomada de decisão, buscará confiabilidade no que está sendo apresentado.

ludícibus (2010, p. 121) menciona "que a essência da evidenciação é oferecer informação quantitativa e qualitativa de maneira ordenada visando uma base adequada de consulta para o usuário".Klan e Beuren (2011) destacam a necessidade de maior comparabilidade e transparência nas informações contábeis devido à expansão do mercado financeiro internacional. O dinamismo dos mercados de capitais ampliou a busca por informações úteis para a tomada de decisão (Neves et al., 2012).

Neste sentido, a globalização dos negócios tornou-se um elemento fundamental para harmonização contábil (Perez Junior, 2009). Bueno e Lopes (2005) conceituam a harmonização contábil como um processo que aproxima as informações, diminuindo a variedade de práticas contábeis e assim contribuindo para esta comparabilidade desejada.

O novo padrão contábil desenvolvido para alinhar a contabilidade internacionalmente é o International Financial Reporting Standards (IFRS). Mackenzie et al. (2013, p. 1) descreve que o objetivo do International Accounting Standards Board (IASB), órgão responsável pela emissão das normas IFRS, é "desenvolver um conjunto único de normas para demonstrações contábeis baseados em princípios bem definidos, resultando em maior qualidade".

No Brasil, o processo de convergência às normas internacionais se deu a partir da Lei no 11.638/2007 e dos Pronunciamentos Técnicos emitidos pelo Comitê de Pronunciamentos Contábeis (CPC). De acordo com Carvalho (2009, p. 6) "a empresa que estiver seguindo o CPC, que propõe detalhamento e orientação sobre como aplicar a Lei ํํ 11.638/07, estará automaticamente aderindo às normas IFRS".

No campo das instituições financeiras, o Banco Central do Brasil (BACEN) mostra o reconhecimento da validade desta harmonização quando determina, por meio do Comunicado 14.259/06, que todos os intermediários financeiros que estão sob sua supervisão, divulguem a partir de 2010, regularmente, suas demonstrações contábeis em acordo com as normas IFRS. 
Segundo Tombini (2013), o uso dos padrões internacionais eleva a qualidade e a transparência das informações contábeis, facilitando o acesso das instituições do Sistema Financeiro Nacional aos mercados financeiros e de capitais internacionais. Da mesma forma, reduz os custos de captação nesses mercados, pois facilita a comparação dos relatórios contábeis das instituições brasileiras com as estrangeiras.

Com isso, as instituições financeiras passaram a ter uma oportunidade de expansão que resulta em crescimento econômico para o país. E este novo cenário, a partir do ano de 2010 , desperta e possibilita a intenção da realização de estudos, que envolvam a compreensão destas normas e seus impactos nas demonstrações contábeis.

Diversos estudos utilizam longas séries históricas para tentar responder as mais diversas questões. Com a mudança de critério contábil, os indicadores utilizados nestes estudos podem ser modificados e distorcer os resultados. Desta forma, é importante compreender o impacto das mudanças em padrões contábeis nos indicadores econômico-financeiros. O setor financeiro é de particular importância, pois muitas vezes são retirados das pesquisas realizadas.

Diante de tal contexto, o objetivo do estudo é avaliar os impactos da adoção das IFRS nos indicadores econômico-financeiros de instituições financeiras brasileiras através da comparação dos indicadores de 2009 publicados em BR-GAAP e os mesmos indicadores republicados em IFRS. Para atingir o objetivo foram estabelecidos os seguintes objetivos específicos: (a) identificar na literatura os indicadores econômicofinanceiros utilizados para análise de instituições financeiras; (b) analisar a variação dos indicadores econômico-financeiros por meio de testes estatísticos; (c) descrever as principais alterações provocadas pela adoção das IFRS na contabilidade das instituições financeiras, assim como elencá-las com os resultados encontrados.

Justifica-se a pesquisa pela necessidade de compreender como mudanças contábeis podem afetar a interpretação econômico-financeira das empresas. As IFRS vieram para reduzir a assimetria informacional entre empresas e usuários das informações contábeis e inclusive para facilitar a compreensão do público internacional, menos familiarizados com os padrões contábeis brasileiros.

Todavia, as melhorias advindas com a adoção das IFRS também trouxeram uma quebra de série histórica de indicadores e relações econômico-financeiras já consolidadas pelos usuários das informações contábeis. Atualmente há uma série de trabalhos que reduzem esse gap para empresas industriais, como os trabalhos de Amrutha, Selvam e Kathiravan, (2019) e Pires e Decourt (2015), mas ainda existe esta lacuna para instituições financeiras no Brasil, que será reduzida com esta pesquisa. A ampliação dos estudos no campo das instituições financeiras, e das normas internacionais de contabilidade no Brasil, subsidiando assim novos estudos e contribuindo como fonte de consulta para investidores, analistas de mercado, profissionais contábeis, instituições financeiras, reguladores e pesquisadores em geral.

Este artigo está estruturado e cinco partes. Inicia-se com esta introdução, passa pela revisão da literatura atinente ao tema e pela apresentação dos principais aspectos metodológicos. O estudo contempla ainda a apresentação e análise dos dados e conclusão. Por fim tem-se a lista das referências utilizadas no desenvolvimento da pesquisa.

\section{Revisão de Literatura}

\subsection{IFRS e o Sistema Financeiro Nacional}

No Sistema Financeiro Nacional a Resolução no 3.786/09, forneceu orientações sobre a primeira adoção das IFRS para as instituições financeiras, e definiu essa adoção aplicável para instituições financeiras abertas ou com comitês de auditoria, requerendo a publicação de demonstrações contábeis em IFRS. Desde então, em atendimento às normas emitidas pelo órgão regulador, essas instituições têm elaborado suas demonstrações segundo dois padrões contábeis: um definido pelo IASB e outro consubstanciado no Plano Contábil das Instituições do Sistema Financeiro Nacional.

O BACEN não autorizou o uso das IFRS nos balanços individuais das instituições financeiras, nem para as demonstrações consolidadas divulgadas junto com as individuais. Para estas, manteve-se o uso do padrão estabelecido pelo COSIF, seguindo as diretrizes das Leis ํos 6.404/76, 11.638/07 e 11.941/09 para contabilização das operações, associadamente às normas da CVM e do CPC, porém priorizando, o formato COSIF para quando houver divergências (Fe Junior, 2013).

Embora não tenha adotado para as instituições financeiras o mesmo procedimento da Comissão de Valores Mobiliários na recepção dos pronunciamentos técnicos emitidos pelo CPC, o BACEN reconhece a necessidade de convergência aos padrões contábeis internacionais, além de ser uma recomendação do comitê da Basileia, tendo em vista a competição no mercado financeiro internacional com informações transparentes e compreensíveis em âmbito mundial.

Em evento patrocinado pelo BACEN, o seu representante afirmou que a instituição reconhece a necessidade de convergência aos padrões contábeis internacionais, no que diz respeito à regulação contábil (Anjos, 2010).

Se a necessidade e relevância de adoção das Normas Internacionais de Contabilidade são reconhecidas pelo órgão regulador, pergunta-se por que a convergência não tem ocorrido da mesma forma 
que na CVM. A justificativa está na particularidade do sistema financeiro. O BACEN tem em sua missão o papel de assegurar a solidez e eficiência do Sistema Financeiro Nacional. Dessa forma, os impactos gerados pela adoção de uma norma devem ser avaliados sob uma ótica macroeconômica.

Ûm fato relevante sobre o assunto, abordado por Gebhardt e Novotny-Farkas (2010) é quanto ao valor justo: eles destacam que esse método de avaliação foi acusado de ter contribuído para exacerbar os efeitos da crise. Contudo, no estudo realizado sobre a qualidade contábil na adoção obrigatória das IFRS em doze bancos europeus, os empréstimos totalizavam cerca de $60 \%$ dos ativos dessas instituições, que são avaliados ao custo.

Já no quesito deterioração do crédito a norma trouxe grande impacto nos resultados apresentados pelas instituições da amostra, o conceito para provisão em IFRS é de perda incorrida e nos Generally Accepted Accounting Principles (GAAPs) locais era de perda esperada. Os resultados encontrados sugerem que a abordagem de perda incorrida leva a um reconhecimento tardio dos créditos de liquidação duvidosa, 0 que poderia resultar em informações menos úteis e transparentes sobre o risco de crédito nas demonstrações contábeis dos bancos. Adiar o reconhecimento em perdas, para períodos em que os fluxos de caixa realizados são reduzidos, pode agravar crises econômicas.

Por fim, há que se ressaltar que as normas editadas pelo IASB têm o propósito de gerar informações voltadas primariamente aos investidores, financiadores e outros credores, enquanto a missão do BACEN, como regulador, não necessariamente estará em sinergia com o objetivo do investidor.

Em resumo, no Brasil, a harmonização de direito ocorreu com o advento da Lei no 11.638/07, e de fato com a obrigatoriedade da utilização das normas. A aderência às normas internacionais traz consigo a expectativa de um aumento no nível de confiança das informações divulgadas, refletindo assim, diretamente na movimentação de recursos no mercado financeiro.

No caso do Brasil, especificamente, é esperado que as novas práticas contábeis provenientes do processo de convergência proporcionem uma maior transparência e qualidade nas informações contábeis apresentadas pelas entidades, que são fortemente marcadas pela regulamentação de organismos governamentais (Calixto, 2010).

\subsection{Estudos Empíricos Nacionais}

Avaliando o contexto nacional, os estudos estão precisamente mais focados em impactos, comparações e nível de aderência da nova normativa contábil. A identificação desses grupos vem ao encontro do estágio de convergência às normas internacionais no Brasil. Observa-se que as empresas vêm enfrentando dificuldades com as alterações dispostas pela legislação e órgãos reguladores.

A maioria dos estudos busca prever, quantificar e explicar as mudanças e possíveis impactos das normas internacionais de contabilidade nas empresas. Neste artigo, o principal segmento analisado foi o financeiro. Autores nacionais como: Klan (2007), Almeida (2010), Valério (2011), Sterzeck (2011), Sayed (2012), Calcado et al. (2013), Silveira (2014) e Farias et al. (2014) realizaram pesquisas sobre o tema, as mais relevantes são citadas na sequência:

Observando indicadores prudenciais e de rentabilidade, Almeida (2010) estudou a reclassificação dos ativos financeiros, e os possíveis impactos nestes indicadores de bancos brasileiros. Com foco na introdução da IFRS 9, realizou-se a simulação da reclassificação dos ativos financeiros, da categoria disponível para venda para valor justo, em uma amostra de 38 bancos, comparando o antes e o depois em cada um dos indicadores. Nos resultados apresentados não se verificou alteração significativa no índice de imobilização, mas quanto ao ROA, ROE e índice de Basileia os testes indicaram que há uma variação estatisticamente significativa.

Outro estudo relacionando instituições financeiras e normas internacionais é quanto ao efeito da convergência sobre o conservadorismo. Sterzeck (2011) analisou o comportamento das instituições financeiras diante das alterações ocorridas no ambiente normativo brasileiro, decorrente do processo de convergência às normas internacionais de contabilidade. Analisou-se o grau de conservadorismo utilizando o modelo proposto por Basu (1997) e o método estatístico de dados em painel. As estatísticas das regressões indicaram um impacto maior do retorno negativo no lucro do que o retorno como um todo, de acordo com o modelo utilizado, isso é um indicador de conservadorismo. No entanto, esses coeficientes não se mostraram estatisticamente significativos. Nesse caso, portanto, os resultados indicaram que não é possível inferir que os lucros contábeis das instituições financeiras foram afetados pela nova norma, com relação ao grau de reconhecimento assimétrico das perdas econômicas e, também, que o lucro contábil reflete, de forma oportuna, o resultado econômico.

Calcado et al. (2013), com o artigo intitulado Indicadores Econômico-Financeiros dos Bancos Brasileiros: Impactos Associados aos Padrões Contábeis do IASB e do BACEN, verificaram a diferença entre os indicadores econômico-financeiros dessas instituições para as demonstrações preparadas nos dois modelos contábeis. A realização dos testes empíricos teve por base as demonstrações contábeis de 2010 e 2011 de dezoito bancos. Foram selecionados indicadores representativos dos blocos de análise da metodologia CAMELS, para os quais foram calculadas as estatísticas descritivas, e aplicados testes de diferenças de médias e de mediana entre os dois padrões. Os resultados apontaram diferenças relevantes 
em relação aos indicadores de imobilização do capital próprio, qualidade das operações de crédito, margem líquida, nível de encaixe obrigatório e exposição líquida em moeda estrangeira, o que pode ser justificado pelas diferenças de parâmetros entre os dois modelos contábeis. Os testes empíricos evidenciaram como a divulgação de uma mesma realidade objetiva pode ser significativamente influenciada, em razão da utilização de modelos contábeis com preceitos de reconhecimento, mensuração e divulgação diferenciados.

Silveira (2014) avaliou se a adoção das normas internacionais de contabilidade resultou na alteração da diversidade dos índices econômico-financeiros de empresas listadas na BOVESPA. Foram utilizadas duas técnicas de análise estatística: variação do coeficiente de variação e o teste de igualdade de médias (ANOVA). Concluiu-se que não foi possível identificar alteração na diversidade dos índices econômico-financeiros das empresas listadas no mercado de capitais do Brasil, antes, durante e após a transição para o IFRS.

Farias et al. (2014) em seu artigo Impactos da Adoção das IFRS nas Demonstrações Consolidadas dos Bancos Listados na BM\&FBovespa, investigou o impacto na representação da situação patrimonial, econômica e financeira de 18 bancos listados na BM\&FBovespa. Observaram-se diferenças significativas nos indicadores de liquidez e qualidade da carteira de crédito, indicando que as demonstrações contábeis elaboradas em IFRS sinalizam menor liquidez e mais baixa qualidade de carteira de crédito, quando comparadas ao BR GAAP. Quanto ao patrimônio líquido, verificou-se que as demonstrações contábeis em BR GAAP são mais conservadoras comparadas às em IFRS.

\subsection{Estudos Empíricos Internacionais}

No que se refere à realização de estudos internacionais referente ao tema, podem ser citados: Ernest \& Young (2005), Miranda (2008), Chiqueto (2008), Gebhardt e Novotny-Farkas (2010), Leventis, Dimitropoulos e Anandarajan (2010), Girbina et al. (2012), Amrutha et al. (2019) e Kraft, Landsman e Shan (2020).

Ernest \& Young com o trabalho IFRS - The Implications for European Banks (2005), divulgaram as principais normas internacionais de contabilidade que provocaram impactos no patrimônio líquido (PL) de 15 instituições financeiras europeias. A IAS 39 - Instrumentos Financeiros: Reconhecimento e Mensuração, causou efeitos combinados de incremento e redução no PL dos bancos. A maioria das elevações se deu pela avaliação a valor justo dos investimentos classificados como "disponíveis para venda", que antes eram avaliados ao custo histórico. Já as reduções foram provocadas principalmente pelo aumento das provisões para perdas nas operações de crédito (loan impairment) e pelo reconhecimento de derivativos como o valor líquido negativo. A IAS 32 ocasionou reduções no PL das instituições financeiras, em decorrências de reclassificações para exigibilidade, de instrumentos financeiros anteriormente classificados no PL como interesses minoritários ou ações preferenciais não patrimoniais. Uma terceira norma que acarretou alterações significativas no PL das instituições analisadas pela Ernest \& Young foi a IAS 19 - Benefícios aos Empregados. Essa norma foi responsável por diminuições nos patrimônios líquidos dos bancos europeus devido ao reconhecimento de déficits em fundos de benefícios a empregados.

Miranda (2008) realizou um estudo que visou identificar a ocorrência de mudanças significativas nos indicadores econômico-financeiros de instituições financeiras da União Europeia após adoção das IFRS. Para isso, os indicadores foram calculados individualmente para cada banco com base no balanço em GAAP local e em normas IFRS (os dois cálculos referiram-se ao mesmo exercício social de 2004). Logo, foram realizadas comparações entre os números calculados nos dois métodos, utilizando teste de hipóteses para diferenças de médias ( $T$-Student) com o objetivo de testar a hipótese de que a diferença entre as médias dos dois conjuntos de indicadores não era significativa. Como resultado se concluiu que a adoção das normas IFRS mostra-se capaz de provocar mudanças significativas nos indicadores de alguns países. A atual pesquisa replicou o estudo para o Brasil.

Focando especificadamente a IAS de número 39, observa-se que Chiqueto (2008) verificou os impactos na provisão para devedores duvidosos dos bancos europeus listados na Bolsa de Nova lorque, após a adoção das IFRS. O trabalho trouxe os principais conceitos que envolvem os critérios de mensuração da provisão para devedores duvidosos, e por meio de técnicas estatísticas, a relevância do impacto no saldo de provisão dos bancos europeus em 2005. Concluiu-se, que a adoção das normas internacionais de contabilidade pelos bancos europeus causou impactos insignificantes no saldo de provisão para devedores duvidosos, independente da relativa semelhança conceitual existente entre o modelo britânico e 0 determinado pela IAS.

Gebhardt e Novotny-Farkas (2010) analisaram as implicações da adoção das IFRS na qualidade dos bancos em doze países da Europa. Investigaram como a aplicação da IAS 39 incorrida em perdas, afeta o principal item de competência operacional (comercial) dos bancos, a perda de crédito à disposição. Além disso, descobriram também que os efeitos da adoção das IFRS são, significativamente, menos pronunciados em regimes de supervisão mais rigorosas e em estruturas de propriedade amplamente mantidas. No último conjunto de análises, confirmaram que os bancos reconhecem créditos de liquidação duvidosa de uma forma menos oportuna, após a adoção das IFRS. Especificamente, usando um teste de persistência do lucro, descobriram que os rendimentos diminuem devido ao aumento nas provisões para perdas com empréstimos não revertidos imediatamente, mas tendem a persistir em períodos futuros. Logo, a abordagem de perda 
incorrida pode fornecer incentivos para os gestores, principalmente durante tempos de bonança, para adiar o reconhecimento de perda de empréstimo para os períodos em que os fluxos de caixa são reduzidos, permitindo-Ihes passar consequências para as gerações subsequentes. Este comportamento pode alimentar ainda mais os lucros bancários e exacerbar as crises econômicas.

Leventis et al. (2010), analisaram também as provisões para perdas de crédito relacionadas ao gerenciamento de ganhos por bancos da União Europeia. O objetivo foi examinar o impacto da implementação das IFRS no uso em perdas de crédito provisionadas para gerenciar ganhos de capital. Utilizaram uma amostra de 91 bancos durante um período de 10 anos (antes e depois da implementação das IFRS). No geral, identificaram que o gerenciamento de resultados (com provisões para perdas com empréstimos) para adotantes precoces ou tardios, é significativamente reduzido após a implementação das IFRS. Do mesmo modo descobriram que, para os bancos de risco, o comportamento de gerenciamento de resultados é mais notável quando comparado com os bancos de menor risco, mas é significativamente reduzido no período pós IFRS. Em geral, pode-se concluir que a implementação das IFRS na União Europeia parece ter melhorado a qualidade do lucro, reduzindo a tendência do gerenciamento de resultados usando as provisões para perdas.

Girbina et al. (2012) estudaram as percepções sobre a preparação dos bancos romenos para implementação das IFRS. O objetivo do estudo foi investigar as percepções dos principais bancos atuantes, sobre os custos e benefícios envolvidos com o uso das IFRS como relatório padrão. Observou-se, que a maioria dos preparadores consideram a aplicação das IFRS positiva no quesito custo-benefício. Entretanto, os mesmos acham a natureza das IFRS complexa e com insuficiente orientação da aplicação, principalmente no que tange a IAS 39, por eles considerada a mais desafiadora. Entre os resultados positivos relacionados no questionário estão: melhor comparabilidade, transparência e confiança para o investidor. Além disso, muitos comentaram que mesmo que não fosse uma exigência da Lei Romena, a adoção ao IFRS seria necessária.

Amrutha et al. (2019) identificaram um impacto significativamente maior sobre os índices contábeis preparados de acordo com as IFRS em comparação com aqueles preparados de acordo com o GAAP.

Kraft et al. (2020) demonstraram que os erros de predição percentual absoluto médio e mediano são maiores para empresas financeiras e não financeiras após a adoção obrigatória das IFRS. Os autores também verificaram que no período pós-adoção, os erros de previsão são maiores para empresas em países com instituições mais fracas, como baixos níveis de direitos de propriedade e acesso mais restritivo ao crédito.

Por ora, não foram encontrados trabalhos no âmbito nacional ou internacional que replicassem o estudo de Miranda (2008) no Brasil. Neste estudo complementou-se a evidenciação dos impactos das normas internacionais nos indicadores econômico-financeiros de instituições financeiras. $O$ estudo nacional mais próximo foi o de Farias et al. (2014).

\section{Procedimentos Metodológicos}

De acordo com o Comunicado 14.259 de 10 de março de 2006, do Banco Central do Brasil, a partir do diagnóstico das transformações no cenário econômico mundial, as quais impuseram a necessidade de convergência às normas internacionais de contabilidade, foram editados procedimentos para elaboração e publicação de demonstrações contábeis consolidadas, em consonância com os pronunciamentos do IASB a partir de 2010.

Segundo Pires e Decourt (2015), para transição completa ao IFRS, em 2010, as companhias tiveram que republicar as demonstrações contábeis do ano de 2009, mostrando a reconciliação entre os dois métodos (BR GAAP e IFRS). Desta forma, as demonstrações financeiras de 2009 proporcionaram uma oportunidade única para um melhor entendimento dos impactos da adoção do IFRS na contabilidade das instituições financeiras brasileiras, já que foi possível comparar mesmos ativos e resultados reportados de acordo com dois diferentes padrões contábeis.

Sendo assim, as unidades de análise neste estudo, trataram-se das dezenove instituições financeiras listadas na BM\&FBovespa no ano de 2009 e que tinham todas as suas demonstrações financeiras referentes ao ano de 2009, e a Caixa Econômica Federal (no ano de 2010 as empresas reapresentaram o ano de 2009, sendo assim, obteve-se as demonstrações contábeis consolidadas em BR GAAP e IFRS referentes ao ano de 2009). A Caixa Econômica Federal, apesar de não estar listada na BM\&FBovespa participa da amostra em virtude de sua representatividade junto à economia nacional.

As empresas que compuseram a amostra foram: Banestes S.A, BCO ABC Brasil S.A, BCO Alfa de Investimento S.A, BCO Bradesco S.A, BCO Brasil S.A, BCO BTG Pactual S.A, BCO Daycoval S.A, BCO Estado do Sergipe S.A, BCO Estado do Rio Grande do Sul S.A, BCO Industrial e Comercial S.A, BCO Indusval S.A, BCO Mercantil do Brasil S.A, BCO Nordeste do Brasil S.A, BCO Patagônia S.A, BCO Pine S.A, BCO Santander (Brasil) S.A, BRB BCO de Brasília S.A, ITAU Unibanco Holding S.A, Paraná BCO S.A e Caixa Econômica Federal.

Trabalhar com os dados de 2009 é uma oportunidade única, pois foi o ano com as alterações mais relevantes e que tiveram seus números publicados em dois padrões contábeis. Nos anos seguintes, continuaram a existir evoluções nas IFRS como uma evolução natural, mas sem a oportunidade de confrontar os números em BR-GAAP e IFRS como tivemos para o exercício contábil de 2009. 
A seleção dos indicadores econômico-financeiros a serem calculados teve por base a revisão bibliográfica destes em nível nacional e internacional, logo foram validados os indicadores selecionados por Miranda (2008) quanto a representatividade no estudo, e julgados relevantes para réplica com base nas demonstrações contábeis das instituições financeiras listadas na BM\&FBovespa.

Incluiu-se um indicador que não foi calculado na dissertação de Miranda (2008), o retorno sobre o patrimônio líquido, este, representa o bloco de rentabilidade e lucratividade. Posteriormente os indicadores econômico-financeiros selecionados foram calculados para as demonstrações contábeis em BR GAAP e IFRS.

\begin{tabular}{|l|l|l|l|}
\hline Bloco & Indicador & Fórmula & Abreviação \\
\hline $\begin{array}{l}\text { Adequação de Capital (estrutura } \\
\text { patrimonial e de captação) }\end{array}$ & $\begin{array}{l}\text { Independência Financeira } \\
\text { (capitalização) }\end{array}$ & Patrimônio Líquido/ Ativo Total & CAP \\
\hline $\begin{array}{l}\text { Adequação de Capital (estrutura } \\
\text { patrimonial e de captação) }\end{array}$ & Empréstimos/Depósitos & Carteira de Crédito/Depósitos Totais & EMPDEP \\
\hline $\begin{array}{l}\text { Adequação de Capital (estrutura } \\
\text { patrimonial e de captação) }\end{array}$ & Alavancagem & Passivo de Terceiros/Patrimônio Líquido & ALAV \\
\hline $\begin{array}{l}\text { Liquidez (solvência) } \\
\text { Liquidez (solvência) }\end{array}$ & Encaixe Voluntário & $\begin{array}{l}\text { Disponibilidades/ Depósitos à Vista } \\
\text { Interfinanceiras de Liquidez/Depósitos à } \\
\text { vista }\end{array}$ & ENCV \\
\hline Liquidez (solvência) & Carteira de Crédito/ Ativo Total & PAREMP \\
\hline $\begin{array}{l}\text { Resultados (rentabilidade e } \\
\text { lucratividade) }\end{array}$ & $\begin{array}{l}\text { Participação dos } \\
\text { Empréstimos } \\
\text { Petorno sobre o }\end{array}$ & Lucro Líquido/Patrimônio Líquido & ROE \\
\hline
\end{tabular}

Figura 1: Listagem de Indicadores Econômico-Financeiros

Fonte: Elaborados pelos autores.

Para verificação do impacto no ano de 2009 da adoção do IFRS foram realizadas análises por meio da comparação das médias de cada um dos indicadores econômico-financeiros calculados em ambos os formatos, BR GAAP e IFRS. Também se realizaram testes estatísticos com a intenção de verificar se as diferenças encontradas eram significativas ou não, apesar da ciência de que dificilmente seria encontrada diferenças significativas em uma amostra com apenas 20 instituições financeiras.

Primeiramente, foi verificada a aderência à normalidade com o teste Shapiro-Wilk. Os resultados encontrados pelo teste $W$ com nível de decisão alfa $=0,05$ sinalizaram que os dados em sua maioria não eram normais. Para expandir a análise também foram considerados resultados entre 0,05 e 0,10, mas ainda assim os dados em sua maioria não se tratava de normais, $42,86 \%$ aceitou H0 (são normais) e $57,14 \%$ rejeitou H0 (não são normais).

Posteriormente, considerando a maior aceitação da hipótese 1 (um), onde os dados não são normalmente distribuídos, optou-se por um teste não paramétrico, Mann Whitney, uma vez que outros testes exigem que a amostra tenha uma distribuição normal.

Os resultados encontrados pelo teste Mann Whitney com nível de decisão alfa =0,05 sinalizaram que não há diferença significativa entre os indicadores calculados em BR GAAP e IFRS. Para expandir a análise, também foram considerados resultados entre 0,05 e 0,10, entretanto manteve-se a afirmação anterior, não foi possível identificar diferenças significativas, o que já era esperado pela pequena amostra com a qual foi possível trabalhar.

Como teste de robustez e por se tratar de uma amostra pequena, foi realizado um teste de proporções, o teste chi-quadrado de Pearson, sugerido por Campbell (2007) para a pesquisa em medicina com amostra pequena devido à raridade de uma condição ou a recursos limitados. A situação nesta pequena amostra de dados contábeis é exatamente a mesma e o teste torna-se adequado.

\section{Apresentação e Análise dos Resultados}

Os sete indicadores econômico-financeiros calculados neste estudo são distribuídos em três blocos: adequação de capital (estrutura patrimonial e de captação), liquidez (solvência), e resultados (rentabilidade e lucratividade). Cada bloco fornece uma visão específica da situação econômico-financeira das instituições financeiras, sendo assim os resultados da pesquisa são apresentados de forma segmentada.

\subsection{Adequação de Capital (Estrutura Patrimonial e Captação)}

Como se pode observar na Tabela 1, a relação entre empréstimos/depósitos (EMPDEP) não apresenta padrão entre os bancos analisados. A média para IFRS é um pouco superior $(5,47 \%)$, mas, 7 
bancos apresentaram redução neste indicador e 13 apresentaram alta, sendo essa diferença não significativa pelo teste qui-quadrado.

Tabela 1:

Indicadores de Empréstimos/Depósitos (EMPDEP), Alavancagem (ALAV) e Capitalização (CAP)

\section{Estrutura Patrimonial e Captação}

\begin{tabular}{|c|c|c|c|c|c|c|c|c|c|}
\hline \multirow[t]{3}{*}{$\begin{array}{l}\text { Instituições } \\
\text { Financeiras } \\
\end{array}$} & \multirow{2}{*}{\multicolumn{2}{|c|}{$\begin{array}{l}\text { Indicador - } \\
\text { Modelo Contábil } \\
\text { EMPDEP } \\
\end{array}$}} & \multirow{3}{*}{$\begin{array}{l}\text { Variação } \\
\text { para } \\
\text { IFRS }\end{array}$} & \multirow{2}{*}{\multicolumn{2}{|c|}{$\begin{array}{l}\text { Indicador - Modelo } \\
\text { Contábil } \\
\text { ALAV } \\
\end{array}$}} & \multirow{3}{*}{$\begin{array}{l}\text { Variação } \\
\text { para } \\
\text { IFRS }\end{array}$} & \multirow{2}{*}{\multicolumn{2}{|c|}{$\begin{array}{l}\text { Indicador - } \\
\text { Modelo Contábil } \\
\text { CAP } \\
\end{array}$}} & \multirow{3}{*}{$\begin{array}{l}\text { Variaçãc } \\
\text { para } \\
\text { IFRS }\end{array}$} \\
\hline & & & & & & & & & \\
\hline & BR GAAP & IFRS & & BR GAAP & IFRS & & BR GAAP & IFRS & \\
\hline 1 & 0,6902 & 0,6544 & $-5,19 \%$ & 12,4477 & 12,0521 & $-3,18 \%$ & 0,0744 & 0,0766 & $2,96 \%$ \\
\hline 2 & 2,4366 & 2,4219 & $0,60 \%$ & 5,0546 & 4,8789 & $-3,48 \%$ & 0,1652 & 0,1701 & $2,97 \%$ \\
\hline 3 & 0,9315 & 0,5948 & $-36,15 \%$ & 9,9293 & 8,8245 & $-11,13 \%$ & 0,0915 & 0,1018 & $11,26 \%$ \\
\hline 4 & 0,6963 & 0,8860 & $27,24 \%$ & 11,1240 & 9,9680 & $-10,39 \%$ & 0,0825 & 0,0912 & $10,55 \%$ \\
\hline 5 & 1,0120 & 0,8744 & $-13,60 \%$ & 18,6169 & 16,3383 & $-12,24 \%$ & 0,0510 & 0,0577 & $13,14 \%$ \\
\hline 6 & 0,2102 & 0,2483 & $18,13 \%$ & 5,7544 & 5,8483 & $1,63 \%$ & 0,1481 & 0,1460 & $-1,42 \%$ \\
\hline 7 & 1,4548 & 1,6074 & $10,49 \%$ & 3,1713 & 2,6975 & $-14,94 \%$ & 0,2397 & 0,2705 & $12,85 \%$ \\
\hline 8 & 0,3914 & 0,3979 & $1,66 \%$ & 14,2293 & 11,3357 & $-20,34 \%$ & 0,0657 & 0,0811 & $23,44 \%$ \\
\hline 9 & 0,8337 & 0,8505 & $2,02 \%$ & 7,5329 & 7,3860 & $-1,95 \%$ & 0,1172 & 0,1192 & $1,71 \%$ \\
\hline 10 & 1,6159 & 1,6895 & $4,55 \%$ & 5,4535 & 5,3474 & $-1,95 \%$ & 0,1550 & 0,1575 & $1,61 \%$ \\
\hline 11 & 1,2442 & 0,9846 & $-20,86 \%$ & 5,3098 & 5,1560 & $-2,90 \%$ & 0,1585 & 0,1624 & $2,46 \%$ \\
\hline 12 & 1,0682 & 1,2508 & $17,09 \%$ & 13,3978 & 20,1401 & $50,32 \%$ & 0,0695 & 0,0473 & $-31,94 \%$ \\
\hline 13 & 0,9533 & 1,4592 & $53,07 \%$ & 8,2412 & 7,6805 & $-6,80 \%$ & 0,1082 & 0,1152 & $6,47 \%$ \\
\hline 14 & 0,6977 & 0,7814 & $12,00 \%$ & 4,4227 & 4,0682 & $-8,02 \%$ & 0,1844 & 0,1973 & $7,00 \%$ \\
\hline 15 & 1,1554 & 1,4361 & $24,29 \%$ & 7,4633 & 8,5135 & $14,07 \%$ & 0,1182 & 0,1051 & $-11,08 \%$ \\
\hline 16 & 1,0741 & 0,8929 & $-16,87 \%$ & 4,3079 & 3,5617 & $-17,32 \%$ & 0,1884 & 0,2192 & $16,35 \%$ \\
\hline 17 & 0,6587 & 0,6104 & $7,33 \%$ & 10,3731 & 11,2235 & $8,20 \%$ & 0,0879 & 0,0818 & $-6,94 \%$ \\
\hline 18 & 1,1632 & 1,1788 & $1,34 \%$ & 11,0014 & 8,7936 & $-20,07 \%$ & 0,0833 & 0,1021 & $22,57 \%$ \\
\hline 19 & 1,2332 & 1,4340 & $16,28 \%$ & 2,3182 & 2,3750 & $2,45 \%$ & 0,3014 & 0,2963 & $-1,69 \%$ \\
\hline 20 & 0,6398 & 1,0085 & $57,63 \%$ & 25,0071 & 20,1700 & $-19,34 \%$ & 0,0385 & 0,0472 & $22,60 \%$ \\
\hline Média & 1,0080 & 1,0631 & $5,47 \%$ & 9,2578 & 8,8179 & $-4,75 \%$ & 0,1264 & 0,1323 & $4,67 \%$ \\
\hline
\end{tabular}

Fonte: Desenvolvido pelos autores

As diferenças nos indicadores Passivo de Terceiros/Patrimônio Líquido (ALAV) e Patrimônio Líquido/ Ativo Total (CAP) apresentaram diferenças percentuais menores, mas com uma consistência maior no padrão entre os bancos analisados, sendo que 16 tiveram queda na relação Passivo de Terceiros/Patrimônio Líquido e apenas 4 deles apresentaram alta. No indicador Patrimônio Líquido/ Ativo Total a relação foi inversa. Estas diferenças de proporção foram significativas a 5\%.

Tabela 2:

Impactos da Adoção das IFRS sobre os indicadores EMPDEP, ALAV e CAP de Instituições Financeira

\begin{tabular}{l|l|l|l|l|l|l|l}
\hline Indicador & $\begin{array}{l}\text { Número de } \\
\text { Observações }\end{array}$ & $\begin{array}{l}\text { Média } \\
\text { BR-GAAP }\end{array}$ & $\begin{array}{l}\text { Média } \\
\text { IFRS }\end{array}$ & $\begin{array}{l}\text { Resultado } \\
\text { Test U }\end{array}$ & $\begin{array}{l}\text { P-valor } \\
\text { bilateral }\end{array}$ & $\begin{array}{l}\text { Proporção } \\
\text { variação } \\
\text { positiva/negativa }\end{array}$ & P-valor \\
\hline EMPDEP & 20 & 1,008 & 1,0631 & 191 & 0,8077 & 1,85 & 0,3434 \\
\hline ALAV & 20 & 9,2578 & 8,8179 & 193 & 0,8498 & 0,20 & 0,0495 \\
\hline CAP & 20 & 0,1264 & 0,1323 & 193 & 0,8498 & 4,00 & 0,0495 \\
\hline
\end{tabular}

Fonte: Elaborado pelos autores

Os indicadores de estrutura patrimonial e de captação demonstraram as origens da sustentação da instituição financeira. De forma geral, quanto maior for o uso de capital de terceiros, maior a incerteza em relação aos resultados esperados, entretanto grande participação de recursos próprios não necessariamente refletirá uma situação favorável (Assaf Neto, 2010; Miranda, 2008). No caso de instituições financeiras, o nível de capital funciona como um mecanismo de proteção aos depositantes.

As contas relacionadas nos indicadores de adequação de capital são: carteira de crédito, depósitos totais, patrimônio líquido, ativo total e passivos de terceiros. O indicador alavancagem mede a proporção do uso de recursos de terceiros, em média as instituições financeiras utilizam 9,3 vezes mais recursos de terceiros que recursos próprios para alavancar seus negócios, segundo as demonstrações contábeis em BR GAAP. Já de acordo com o padrão internacional, as instituições financeiras utilizam 8,8 vezes mais recursos de terceiros, evidenciando uma alavancagem média menor em IFRS do que em BR GAAP. Essas diferenças 
foram motivadas, principalmente, pela mensuração a valor justo das operações de crédito e dos derivativos e pela menor provisão para créditos de liquidação duvidosa, efetuada nas demonstrações em IFRS. Esta tendência de uma redução na alavancagem das instituições financeiras foi significativa como pode ser observado pelo teste chi-quadrado, todavia a diferença não foi grande o suficiente para encontrar em diferença significativa com uma amostra de apenas 20 instituições financeiras.

Em relação ao indicador capitalização (CAP) também conhecido como independência financeira, às estatísticas descritivas demonstram que, a utilização dos padrões estabelecidos pelo IASB resulta em maior proporção do patrimônio líquido em relação aos ativos totais.

O índice capitalização representa a parcela do ativo total coberta pelos recursos próprios da empresa. Em média, as instituições financeiras apresentam índice capitalização 0,1264, tomando-se por base as demonstrações contábeis em BR GAAP, e 0,1323, considerando-se as demonstrações contábeis em IFRS. Isso indica que o patrimônio líquido dessas instituições financeiras cobre em média $13 \%$ dos seus ativos (considerando padrão brasileiro e/ou IFRS), mas que, com a adoção das IFRS é possível visualizar um aumento de 4,67\% nesta relação. As principais causas das diferenças no PL são: (i) BR GAAP excluía a participação dos acionistas controladores, no IFRS considera-se; (ii) ajuste ao valor recuperável de empréstimos e adiantamentos (carteira de crédito); (iii) ajuste ao valor justo de ativos financeiros constantes da carteira de fundos de investimentos exclusivos consolidados; (iv) ajuste a valor justo dos ativos financeiros - títulos de patrimônio; (v) constituição de crédito tributário sobre diferença de alíquota; e (vi) imposto de renda e contribuição social diferidos sobre ajuste de IFRS. O teste chi-quadrado reforça a percepção de aumento nesta relação, mas de novo o tamanho do aumento não é suficiente para que a diferença seja significativa.

Para o indicador empréstimos/depósitos os resultados confirmam os resultados dos estudos de Miranda (2008) e Farias et al. (2014). No estudo de Farias et al. (2014), observou-se resultados diferentes para os indicadores de alavancagem e capitalização, assim como no estudo de Miranda (2008), entretanto salienta-se que para Miranda (2008) não foram em todos os países que as diferenças foram relevantes. Aqui no Brasil, nem mesmo uma tendência de aumento ou redução pode ser observada.

\subsection{Liquidez (Solvência)}

Tabela 3:

Indicadores de Encaixe Voluntário (ENCV), Liquidez Imediata (LIQIME) e Participação dos Empréstimos (PAREMP)

\section{Solvência}

\begin{tabular}{|c|c|c|c|c|c|c|c|c|c|}
\hline \multirow[t]{3}{*}{$\begin{array}{l}\text { Instituições } \\
\text { Financeiras } \\
\end{array}$} & \multirow{2}{*}{\multicolumn{2}{|c|}{$\begin{array}{l}\text { Indicador - } \\
\text { Modelo Contábil } \\
\text { ENCV } \\
\end{array}$}} & \multirow{3}{*}{\begin{tabular}{|l|} 
\\
Variação \\
Para \\
IFRS
\end{tabular}} & \multirow{2}{*}{\multicolumn{2}{|c|}{$\begin{array}{l}\text { Indicador - } \\
\text { Modelo Contábil } \\
\text { LIQIME } \\
\end{array}$}} & \multirow{3}{*}{$\begin{array}{l}\text { Variação } \\
\text { para } \\
\text { IFRS }\end{array}$} & \multirow{2}{*}{\multicolumn{2}{|c|}{$\begin{array}{l}\text { Indicador - } \\
\text { Modelo Contábil } \\
\text { PAREMP } \\
\end{array}$}} & \multirow{3}{*}{$\begin{array}{l}\text { Variação } \\
\text { para } \\
\text { IFRS }\end{array}$} \\
\hline & & & & & & & & & \\
\hline & BR GAAP & IFRS & & BR GAAP & IFRS & & BR GAAP & IFRS & \\
\hline 1 & 0,5242 & 0,5242 & $0,00 \%$ & 3,4087 & 3,4087 & $0,00 \%$ & 0,3870 & 0,3550 & $-8,27 \%$ \\
\hline 2 & 0,2827 & 0,2827 & $0,00 \%$ & 3,2975 & 3,0182 & $-8,47 \%$ & 0,7757 & 0,7740 & $-0,22 \%$ \\
\hline 3 & 0,0031 & 0,0034 & $9,68 \%$ & 0,0961 & 0,0433 & $-54,94 \%$ & 0,3996 & 0,4342 & $8,66 \%$ \\
\hline 4 & 0,7182 & 0,7264 & $1,14 \%$ & 2,9065 & 3,1359 & $7,89 \%$ & 0,4287 & 0,5248 & $22,42 \%$ \\
\hline 5 & 0,5690 & 0,5311 & $-6,66 \%$ & 3,5104 & 2,6582 & $-24,28 \%$ & 0,3695 & 0,4071 & $10,18 \%$ \\
\hline 6 & 0,0160 & 0,0154 & $-3,75 \%$ & 3,0591 & 3,0299 & $-0,95 \%$ & 0,0626 & 0,0548 & $12,46 \%$ \\
\hline 7 & 0,4890 & 0,4952 & $1,27 \%$ & 0,9137 & 0,8867 & $2,96 \%$ & 0,4908 & 0,5948 & $21,19 \%$ \\
\hline 8 & 0,1336 & 0,1569 & $17,44 \%$ & 0,6894 & 0,6998 & $1,51 \%$ & 0,3280 & 0,3313 & $1,01 \%$ \\
\hline 9 & 0,8382 & 0,8382 & $0,00 \%$ & 3,3882 & 2,4930 & $26,42 \%$ & 0,4692 & 0,4699 & $0,15 \%$ \\
\hline$\overline{10}$ & 0,9262 & 0,9306 & $0,48 \%$ & 3,8032 & 2,1800 & $-42,68 \%$ & 0,8238 & 0,8748 & $6,19 \%$ \\
\hline 11 & 0,1489 & 0,1474 & $-1,01 \%$ & 0,8674 & 0,6100 & $-29,67 \%$ & 0,5754 & 0,5817 & $1,09 \%$ \\
\hline 12 & 0,0502 & 0,0532 & $5,98 \%$ & 0,7270 & 0,7300 & $0,41 \%$ & 0,5794 & 0,5673 & $-2,09 \%$ \\
\hline 13 & 0,5971 & 0,5971 & $0,00 \%$ & 1,7067 & 1,2708 & $25,54 \%$ & 0,3373 & 0,4978 & $47,58 \%$ \\
\hline 14 & 0,2400 & 0,2213 & $7,79 \%$ & 0,7610 & 0,3516 & $-53,80 \%$ & 0,4729 & 0,5478 & $15,84 \%$ \\
\hline$\overline{15}$ & 0,0496 & 0,0456 & $8,06 \%$ & 1,0623 & 0,9037 & $14,93 \%$ & 0,4605 & 0,5673 & $23,19 \%$ \\
\hline$\overline{16}$ & 0,1248 & 0,0714 & $-42,79 \%$ & 1,0930 & 0,6460 & $-40,90 \%$ & 0,3560 & 0,4816 & $35,28 \%$ \\
\hline 17 & 0,0197 & 0,0202 & $2,54 \%$ & 0,4485 & 0,4558 & $1,63 \%$ & 0,4909 & 0,4574 & $-6,82 \%$ \\
\hline 18 & $\mathrm{p}, 1282$ & 0,1287 & $0,39 \%$ & 0,8579 & 1,5422 & $79,76 \%$ & 0,3648 & 0,3886 & $6,52 \%$ \\
\hline 19 & $\mathrm{p}, 1736$ & 0,1735 & $-0,06 \%$ & 0,2216 & 0,2203 & $-0,59 \%$ & 0,4700 & 0,5225 & $11,17 \%$ \\
\hline 20 & 0,1566 & 0,1571 & $0,32 \%$ & 0,9757 & 0,8109 & $-16,89 \%$ & 0,3379 & 0,5292 & $56,61 \%$ \\
\hline Média & 0,3095 & 0,3060 & $1,13 \%$ & 1,6897 & 1,4547 & $-13,91 \%$ & 0,4490 & 0,4981 & $10,94 \%$ \\
\hline
\end{tabular}

Fonte: Elaborado pelos autores 
O indicador Disponibilidades/ Depósitos à Vista (ENCV) não mostra nenhuma tendência bem definida. Há um pouco mais de casos de aumento de liquidez pelos critérios das IFRS em relação ao BR-GAAP, mas quando a diferença é negativa, os valores são maiores, o que leva a média ser negativa. A grande maioria das diferenças é inferior à 10\%, o que reforça a ideia de que as IFRS tiveram impacto relevante em classificar os ativos como disponibilidades.

Já a classificação de Liquidez Imediata aparentemente foi mais afetada pelas IFRS. A grande maioria das instituições financeiras tiveram variação negativa, mas não em quantidade suficiente para dizer que a diferença é significativa. O mesmo efeito ocorre com a participação dos empréstimos, que teve um aumento médio superior a 10\% e aumentou na maioria das instituições financeiras, mas não o suficiente para termos uma diferença significativa.

Tabela 4:

Impactos da Adoção das IFRS sobre os Indicadores de ENCV, LIQIME e PAREMP de Instituições Financeiras

\begin{tabular}{l|l|l|l|l|l|l|l}
\hline Indicador & $\begin{array}{l}\text { Número de } \\
\text { Observações }\end{array}$ & $\begin{array}{l}\text { Média } \\
\text { BR-GAAP }\end{array}$ & $\begin{array}{l}\text { Média } \\
\text { IFRS }\end{array}$ & $\begin{array}{l}\text { Resultado } \\
\text { Test U }\end{array}$ & $\begin{array}{l}\text { P-valor } \\
\text { bilateral }\end{array}$ & $\begin{array}{l}\text { Proporção } \\
\text { variação } \\
\text { positiva/negativa }\end{array}$ & P-valor \\
\hline ENCV & 20 & 0,3095 & 0,306 & 197 & 0,9353 & 1,29 & 0,72730 \\
\hline LIQIME & 20 & 1,6897 & 1,4547 & 166,5 & 0,3648 & 0,36 & 0,13800 \\
\hline PAREMP & 20 & 0,449 & 0,4981 & 145 & 0,1368 & 3,00 & 0,10690 \\
\hline
\end{tabular}

Fonte: Elaborado pelos autores

Os indicadores de liquidez têm como função revelar a capacidade da instituição financeira em transformar seus ativos em caixa, de maneira a atender adequadamente as suas obrigações financeiras. Quando observados os valores reais das contas relacionadas nestes indicadores é possível visualizar as normas que os alteraram. As contas relacionadas são: disponibilidades, aplicações financeiras, carteira de crédito, ativo total e depósitos.

A variação nos resultados dos indicadores de encaixe voluntário (ENCV) e liquidez imediata (LIQIME) deram-se em virtude da classificação de equivalente de caixa e bases de consolidação. No padrão IFRS, as operações compromissadas e aplicações interfinanceiras de liquidez são consideradas equivalentes de caixa. Para que uma aplicação seja qualificada como equivalente de caixa, de acordo com a IAS 7, o valor deve ser prontamente conversível em caixa e apresentar risco insignificante de mudança de valor justo. Além disso, o recurso deve respeitar um vencimento menor ou igual há três meses, a partir da data de aquisição. As médias são estatisticamente maiores no modelo BR GAAP. A variação do indicador de ENCV foi pequena $(-1,13 \%)$ e não representou diferença estatisticamente significativa, assim como nos estudos de Miranda (2008) e Farias et al. (2014).

O resultado do indicador LIQIME apresentou uma variação bem maior (-13,91\%), em virtude das alterações nos grupos de contas Ativos Líquidos, mas ainda assim não foi possível encontrar diferença significativa. Observou-se a mesma tendência encontrada no estudo de Miranda (2008), entretanto acreditase que em virtude do tamanho da amostra não se confirmaram os mesmos resultados, mudanças estatisticamente significativas. Comparando com estudo de Farias et al. (2014) o presente estudo confirma a inexistência de diferenças significativas.

Os dados analisados mostram que o indicador de participação dos empréstimos (PAREMP) é menor no modelo BR GAAP quando comparado com o padrão IFRS. Isso quer dizer que a utilização do modelo do IASB implicou em maior participação das operações de crédito sobre o ativo da instituição. Esta situação fundamenta-se, principalmente, por meio das provisões para as operações de crédito, que no modelo IFRS foram inferiores àquelas constituídas segundo os parâmetros do BR GAAP. Os testes de diferenças de médias indicam que as diferenças apresentadas não são estatisticamente relevantes, assim como no estudo de Miranda (2008), entretanto não se confirma o mesmo no estudo de Farias et al. (2014).

Nas notas explicativas das demonstrações contábeis em IFRS (2010) do Bradesco S/A, elenca-se as principais mudanças entre o BR GAAP e o IFRS: a Consolidação: nas reconciliações apresentadas pelas instituições financeiras é demonstrada a nova base de consolidação, que interfere positivamente ou negativamente no saldo; e na carteira de crédito ocorrem impactos referentes a IAS 32 e 39, estas relacionam: O diferimento de taxas de serviços financeiros e custos diretos, e a perda por redução ao valor recuperável,

As instituições financeiras trabalham com o conceito de perda esperada e não incorrida. Este novo entendimento pode gerar em longo prazo surpresas para as instituições financeiras, lucros excedentes em uma data, com prejuízo significativo em outra.

A redução das provisões para créditos de liquidação duvidosa e inclusão do ajuste da taxa efetiva de juros aumentou a representatividade da carteira de crédito perante o ativo total de $45 \%$ em BR GAAP para $50 \%$ em IFRS, entretanto estatisticamente não se confirmou a significância desta variação.

\subsection{Resultados (Rentabilidade e Lucratividade)}

Um indicador de rentabilidade busca evidenciar o retorno financeiro que as atividades da empresa proporcionam. Neste estudo foi selecionado o indicador retorno sobre o patrimônio líquido (ROE), a 
composição da amostra foi reduzida comparada com os demais indicadores econômico-financeiros. Neste, o número de observações foram treze, pois sete das instituições financeiras não reapresentaram o lucro líquido de 2009, impossibilitando o cálculo.

Tabela 5:

Indicador de Retorno sobre o Patrimônio Líquido (ROE)

\section{Rentabilidade e Lucratividade}

\begin{tabular}{l|l|l|l}
\hline Instituições Financeiras & \multicolumn{2}{|l|}{ Indicador - Modelo Contábil } & \\
\hline & \multicolumn{1}{|l|}{ ROE } & \multicolumn{2}{l}{ Variação para IFRS } \\
\hline 1 & BR GAAP & IFRS & \\
\hline 2 & 0,1992 & 0,2110 & $5,92 \%$ \\
\hline 3 & 0,1241 & 0,1214 & $2,18 \%$ \\
\hline 5 & 0,0783 & 0,0684 & $-12,64 \%$ \\
\hline 6 & 0,1919 & 0,1859 & $-3,13 \%$ \\
\hline 10 & 0,2809 & 0,3326 & $18,41 \%$ \\
\hline 11 & 0,2499 & 0,1228 & $-50,86 \%$ \\
\hline 14 & 0,1801 & 0,1191 & $-33,87 \%$ \\
\hline 15 & 0,0295 & 0,0447 & $51,53 \%$ \\
\hline 16 & 0,2215 & 0,1391 & $-37,20 \%$ \\
\hline 20 & 0,2421 & 0,2440 & $0,78 \%$ \\
\hline Média & 0,1031 & 0,1722 & $67,02 \%$ \\
\hline Font: & 0,0280 & 0,0795 & $183,93 \%$ \\
\hline
\end{tabular}

Fonte: Elaborado pelos autores

No modelo BR GAAP o retorno sobre o patrimônio líquido em sete das treze instituições financeiras foi maior em relação ao modelo IFRS. O exame analítico dos saldos contábeis revela que o ajuste a valor justo dos ativos financeiros foi o item mais expressivo a implicar em aumento do patrimônio líquido no modelo IFRS. Outro ajuste que refletiu em um patrimônio líquido maior nas demonstrações em IFRS está relacionado à participação dos acionistas não controladores. O teste de diferença de médias não apontou diferença estatisticamente significativa entre os dois padrões contábeis, assim como no estudo de Farias et al. (2014).

Tabela 6:

Impactos da adoção das IFRS sobre o indicador ROE de Instituições Financeiras

\begin{tabular}{l|l|l|l|l|l|l|l}
\hline Indicador & $\begin{array}{l}\text { Número de } \\
\text { observações }\end{array}$ & $\begin{array}{l}\text { Média BR- } \\
\text { GAAP }\end{array}$ & $\begin{array}{l}\text { Média } \\
\text { IFRS }\end{array}$ & $\begin{array}{l}\text { Resultado } \\
\text { Teste U }\end{array}$ & $\begin{array}{l}\text { P-valor } \\
\text { bilateral }\end{array}$ & $\begin{array}{l}\text { Variação } \\
\text { para IFRS }\end{array}$ & $\begin{array}{l}\text { Diferença } \\
\text { significativa }\end{array}$ \\
\hline ROE & 13 & 0,1659 & 0,1560 & 73 & 0,5554 & B>IFRS & Não \\
\hline
\end{tabular}

Fonte: Elaborado pelos autores

Posteriormente, foi desenvolvida a tabela 7, a mesma objetivou uma análise de possíveis tendências nos indicadores econômico-financeiros.

Tabela 7:

Variações e Tendências

\begin{tabular}{|c|c|c|c|c|c|c|c|c|c|}
\hline Indicador & & \multicolumn{2}{|c|}{ EMPDEP } & \multicolumn{2}{|l|}{ ALAV } & \multicolumn{2}{|r|}{ CAP } & \multicolumn{2}{|l|}{ ENCV } \\
\hline $\begin{array}{l}\text { Variação } \\
\text { BR GAAP }\end{array}$ & IFRS - & $\begin{array}{l}\text { № de } \\
\text { IF's }\end{array}$ & $\begin{array}{l}\text { Variação } \\
\%\end{array}$ & \begin{tabular}{|l} 
\\
No de \\
IF's
\end{tabular} & $\begin{array}{l}\text { Variação } \\
\%\end{array}$ & $\begin{array}{l}\text { No de } \\
\text { IF's }\end{array}$ & $\begin{array}{l}\text { Variação } \\
\%\end{array}$ & $\begin{array}{l}\text { № de } \\
\text { IF's }\end{array}$ & $\begin{array}{l}\text { Variação } \\
\%\end{array}$ \\
\hline IFRS > BR GAAP & & 13 & 65 & 5 & 25 & 15 & 75 & 9 & 45 \\
\hline IFRS $<$ BR GAAP & & 7 & 35 & 15 & 75 & 5 & 25 & 7 & 35 \\
\hline IFRS = BR GAAP & & 0 & 0 & 0 & p & 0 & $p$ & 4 & 20 \\
\hline TOTAL & & 20 & 100 & 20 & 100 & 20 & 100 & 20 & 100 \\
\hline Indicador & & \multicolumn{2}{|c|}{ LIQIME } & \multicolumn{2}{|c|}{ PAREMP } & \multicolumn{2}{|r|}{ ROE } & \multicolumn{2}{|c|}{ TOTAL } \\
\hline $\begin{array}{l}\text { Variação } \\
\text { BR GAAP } \\
\end{array}$ & IFRS - & $\begin{array}{l}N o \text { de } \\
\text { IF's }\end{array}$ & $\begin{array}{l}\text { Variação } \\
\%\end{array}$ & $\begin{array}{l}\text { No de } \\
\text { IF's }\end{array}$ & $\begin{array}{l}\text { Variação } \\
\%\end{array}$ & $\begin{array}{l}\text { № de } \\
\text { IF's }\end{array}$ & $\begin{array}{l}\text { Variação } \\
\%\end{array}$ & & $\begin{array}{l}\text { Variação } \\
\%\end{array}$ \\
\hline IFRS > BR GAAP & & 5 & 25 & 15 & 75 & 6 & 46 & 68 & 51 \\
\hline IFRS $<$ BR GAAP & & 14 & 70 & 5 & 25 & 7 & 54 & 60 & 45 \\
\hline IFRS = BR GAAP & & 1 & 5 & 0 & 0 & 0 & 0 & 5 & 4 \\
\hline TOTAL & & 20 & 100 & 20 & 100 & 13 & 100 & 133 & 100 \\
\hline
\end{tabular}

Fonte: Elaborado pelos autores 
Conforme apresentado na tabela 7 de observação de tendências, foi possível identificar que indicadores como EMPDEP, CAP, PAREMP quando calculados para as instituições financeiras após a aderência das normas internacionais, apresentaram resultados superiores em IFRS, considerando respectivamente para cada indicador $75 \%, 65 \%$ e $75 \%$, acredita-se em uma forte tendência de representatividade maior ainda para os próximos períodos. Assim como para os indicadores ALAV (75\%) e LIQIME (70\%), aonde o efeito foi inverso, as normas internacionais reduziram os números reais quando comparados ao BR GAAP, e esse cenário se confirmou para um percentual significativo das instituições financeiras.

Apenas indicadores como ROE, aonde a amostra foi reduzida e ENCV aonde $20 \%$ das instituições financeiras não alteraram os números reais quando comparados BR GAAP e IFRS não foi possível observar uma tendência relevante de aumento ou redução com a adoção das normas internacionais.

Entretanto é possível visualizar as principais normas internacionais que provocaram mudanças nos indicadores estudados: IAS 7, IAS 19, IAS 32, IAS 39. Na tabela 8 apresentamos os principais impactos de cada International Accounting Standards.

Tabela 8:

Impacto dos International Accounting Standards nos indicadores

\begin{tabular}{|c|c|c|}
\hline Norma & Indicador & Impacto \\
\hline \multirow{2}{*}{ IAS 7} & indicadores de encaixe voluntário & \multirow{2}{*}{$\begin{array}{l}\text { Reduz a liquidez das instituições financeiras, pois Para } \\
\text { que uma aplicação seja qualificada como equivalente de } \\
\text { caixa, de acordo com a IAS } 7 \text {, o valor deve ser } \\
\text { prontamente conversível em caixa e apresentar risco } \\
\text { insignificante de mudança de valor justo. }\end{array}$} \\
\hline & liquidez imediata & \\
\hline \multirow{2}{*}{ IAS 39} & custos diretos & \multirow{2}{*}{$\begin{array}{l}\text { Títulos avaliados ao valor justo por meio do resultado e } \\
\text { emprés timos e recebíveis são avaliados ao custo } \\
\text { amortizado. }\end{array}$} \\
\hline & perda por redução ao valor recupe & \\
\hline IAS 32 & $\begin{array}{l}\text { diferimento de taxas de serviços } \\
\text { financeiros }\end{array}$ & $\begin{array}{l}\text { Ocasionou reduções no PL das instituições financeiras, } \\
\text { em decorrências de reclassificações para exigibilidade, } \\
\text { de instrumentos financeiros anteriormente classificados } \\
\text { no PL como interesses minoritários ou ações } \\
\text { preferenciais não patrimoniais. }\end{array}$ \\
\hline \multirow{2}{*}{ IAS 19} & $\begin{array}{l}\text { Independência Financeira } \\
\text { (capitalização) }\end{array}$ & \multirow{2}{*}{$\begin{array}{l}\text { Benefícios aos Empregados. Essa norma foi } \\
\text { responsável por diminuições nos patrimônios líquidos } \\
\text { dos bancos devido ao reconhecimento de déficits em } \\
\text { fundos de benefícios a empregados. }\end{array}$} \\
\hline & $\begin{array}{l}\text { Retorno sobre o } \\
\text { Patrimônio Líquido }\end{array}$ & \\
\hline
\end{tabular}

Fonte: Elaborado pelos autores

Confirma-se, mesmo sem a identificação de mudanças significativas, que as IFRS favoreceram o crescimento do patrimônio líquido e da carteira de crédito, desta forma, os indicadores com essas variáveis no numerador apresentaram valores maiores e os indicadores com essas variáveis no denominador apresentaram valores menores. Já o montante de depósitos totais e aplicações interfinanceiras de liquidez tenderam a diminuir quando aplicadas as normas IFRS. Aparentemente a nova normativa contábil alterou o conservadorismo das instituições financeiras.

Acredita-se que em uma pesquisa de escala longitudinal, será possível visualizar os reflexos nos indicadores econômico-financeiros de instituições financeiras, visto que, as normas internacionais trouxeram novos conceitos, e estes serão melhores aplicados conforme a estabilização e uso do método IFRS.

Lembra-se que para algumas instituições financeiras, o ano de 2009 foi o primeiro com a adoção das IFRS, sendo assim, espera-se uma melhor adaptação nos próximos anos, até mesmo quanto às declarações em notas explicativas referentes à aplicação.

Também se faz acreditar que, com maior recepção e incorporação das normas internacionais por parte do Banco Central do Brasil, as instituições financeiras poderão concentrar esforços em um sentido único, pois assim como no ano de 2009, até os dias atuais, as instituições financeiras mantém suas demonstrações contábeis em BR GAAP (logo adaptado e extraído os dados COSIF) e em IFRS.

\section{Considerações Finais}

O objetivo do presente estudo foi o de avaliar os impactos da adoção das IFRS nos indicadores econômico-financeiros de instituições financeiras brasileiras. Foram comparadas demonstrações contábeis referentes ao mesmo ano, utilizando padrões contábeis diferentes. 
Para os indicadores econômico-financeiros encaixe voluntário, liquidez imediata, alavancagem e retorno sobre o patrimônio líquido, às médias dos resultados foram superiores no formato BR GAAP, enquanto para participação empréstimos, empréstimos/depósitos e capitalização, as médias maiores foram encontradas em IFRS. A quantidade de instituições financeiras que apresentaram aumento nestes indicadores superou o número de empresas que tiveram redução nesses indicadores. Esta diferença foi significativa.

Quanto à variação nos resultados dos indicadores de encaixe voluntário e liquidez imediata relacionase a nova classificação de equivalente de caixa. Também se identifica que as instituições financeiras têm o indicador de alavancagem inferior no formato IFRS, isso define que os recursos de terceiros têm menor significância quando adotadas as normas internacionais. Essas diferenças motivam-se principalmente, pelo reflexo da mensuração do valor recuperável das operações de crédito e dos derivativos, e pela menor provisão para créditos de liquidação duvidosa efetuada nas demonstrações em IFRS.

O retorno sobre o patrimônio líquido é superior quando calculado em acordo com a normativa local. A variação é originada da aplicação do conceito de valor justo nos ativos financeiros. Além disso, o patrimônio líquido sofre também, reflexos da participação dos acionistas não controladores.

Para os indicadores em que as médias foram superiores em IFRS, observou-se principalmente a variação das provisões para as operações de crédito, que no modelo IFRS foram inferiores àquelas constituídas segundo os parâmetros do BR GAAP. O indicador de participação dos empréstimos mostrou que a utilização do modelo do IASB implica em dar maior participação das operações de crédito sobre o ativo da instituição.

Estas variações explicam grande parte das diferenças identificadas, mas para verificar se este é realmente um padrão das IFRS em relação ao BR-GAAP, sugere-se que novas pesquisas se aprofundem nestes aspectos.

Em relação ao indicador capitalização, a utilização dos padrões estabelecidos pelo IASB resultou em uma proporção maior do patrimônio líquido em relação aos ativos totais. O índice de capitalização indicou que o patrimônio líquido dessas instituições financeiras cobriu 13,23\% dos seus ativos, enquanto em BR GAAP $12,64 \%$. As causas relacionadas para estas diferenças foram: em BR GAAP exclui-se a participação dos acionistas controladores, e no IFRS considera-se, a aplicação do ajuste ao valor recuperável de empréstimos e adiantamentos (carteira de crédito), do ajuste ao valor justo de ativos financeiros constantes da carteira de fundos de investimentos exclusivos consolidados, do ajuste a valor justo dos ativos financeiros - títulos de patrimônio, da constituição de crédito tributário sobre diferença de alíquota, do imposto de renda e da contribuição social diferidos sobre ajuste de IFRS. Esta é uma diferença relevante entre os dois padrões contábeis que aumenta a proporção do patrimônio líquido em relação aos ativos totais.

Para o indicador empréstimos/depósitos o reflexo das IFRS foi fundamentado na alteração na carteira de crédito em virtude das provisões. Considera-se com base no estudo desenvolvido que a adoção das normas internacionais do ponto de vista da carteira de crédito torna as demonstrações contábeis menos conservadoras, pois posterga o registro das perdas, refletindo nos resultados.

Comparando a pesquisa atual com estudo internacional de Miranda (2008), os indicadores de solvência, encaixe voluntário e participação de empréstimos confirmaram os resultados. Para o indicador de liquidez imediata não foi possível confirmar mediante amostra trabalhada e com a proporção entre variações positivas e negativas semelhantes.

$\mathrm{Na}$ estrutura patrimonial e de captação, os três indicadores no estudo desenvolvidos não apresentaram diferenças relevantes entre as médias, contrariando os resultados gerais do estudo de Miranda (2008) quanto a dois indicadores, alavancagem e capitalização.

Outro estudo relevante para realização de comparação foi o de Farias et al. (2014) que também calculou os indicadores econômico-financeiros para instituições financeiras brasileiras, mas com uma metodologia diferente, baseado em dados do ano de 2010 e variações amostrais. Quanto à significância das diferenças das médias, foram confirmadas apenas para participação dos empréstimos, alavancagem e capitalização. No estudo observa-se a alteração na qualidade da carteira de crédito, que é resultado das provisões para devedores duvidosos, eles também identificaram uma menor liquidez no formato IFRS.

Elencando os estudos relacionados à pesquisa atual, vem ao encontro dos resultados encontrados o de Chiqueto (2008), ele analisou as novas regras da provisão para devedores duvidosos, e o de Valério (2011), que confirmou que em termos estruturais as demonstrações contábeis já se alteraram bastante, mas que o IFRS ainda precisa ser mais detalhado para uma adequada interpretação. Sterzeck (2011) na mesma linha, comparou os lucros contábeis em ambas às normativas, e Sayed (2012) buscou evidenciar o impacto do valor justo, mais recentemente, Silveira (2014) avaliou se existia variação na diversidade dos indicadores econômico-financeiros em períodos anteriores ou posteriores a adoção das IFRS, todos os autores relacionados não encontraram resultados que afirmassem significativamente 0 impacto das normas internacionais, mas possibilitou-se visualizar a aplicação das novas normas.

O presente estudo atendeu o objetivo geral de verificar a ocorrência de impactos da adoção das IFRS nos indicadores econômico-financeiros de instituições financeiras, sendo importante destacar o percentual representativo de instituições financeiras que tiveram seus indicadores impactados na mesma direção. Em média $72 \%$ das instituições financeiras apresentaram tendências semelhantes para os indicadores 
analisados. Apenas o indicador ROE, aonde a amostra analisada foi menor, e o ENCV, aonde $20 \%$ das instituições financeiras apresentaram números iguais antes e após a adoção das normas, não foi possível traçar uma tendência.

Algumas considerações são quanto à abordagem de perda incorrida, relacionada inúmeras vezes quando avaliada a carteira de crédito. Conforme Gebhardt e Novotny-Farkas (2010) afirmaram, este conceito pode fornecer incentivos para os gestores em tempos de bonança, adiando o reconhecimento de perdas em empréstimos para os períodos em que os fluxos de caixa são reduzidos. Este comportamento pode alimentar falsos lucros bancários, e assim exacerbar as crises econômicas, relacionou-se este entendimento com a posição do Banco Central do Brasil quanto à recepção das normas internacionais: as IFRS vêm sendo aderidas com cautela e constante avaliação dos impactos econômicos.

Um ponto positivo visualizado por autores é quanto à possibilidade de redução da tendência ao gerenciamento de resultados, pois em BR GAAP o uso das provisões para perdas poderia ter este propósito (Leventis et al., 2010). Nesta pesquisa não foi identificado nenhum indício do uso provisões para perdas para modificar o lucro líquido.

Sobre a ótica do método IFRS, os acionistas e investidores estarão conhecendo resultados menos conservadores, que são positivamente recebidos, enquanto a normativa BR GAAP proporcionará aos administradores das instituições financeiras, uma posição mais conservadora, tanto no recolhimento de tributos, quanto na remuneração dos acionistas.

Para os acionistas e investidores, conforme já mencionado por Carvalho (2009), acredita-se que a transição para o padrão IFRS, já proporcionou informações mais transparentes, em virtude da extensão das interpretações e aplicações, conforme relacionadas no decorrer do presente estudo. Quanto à redução do custo de capital e aumento na geração de valor da instituição, observa-se que primeiramente seria necessária uma adoção mais representativa por parte do Banco Central do Brasil das normas internacionais, fazendo assim com que as instituições financeiras unissem esforços em um sentido único que atenda a legislação local e o mercado de capitais.

No entanto, vale lembrar as particularidades do sistema financeiro. O BACEN tem como missão assegurar a solidez e eficiência do sistema, desta maneira a avaliação das IFRS e seus impactos acontecem sob uma ótica macroeconômica, e não na velocidade esperada pelos demais. Ao encontro, Gebhardt e Novotny-Farkas (2010) relacionam que em regimes de supervisão mais rigorosos, os efeitos da adoção das IFRS podem ser menos pronunciados. As pequenas variações que encontramos aqui no Brasil, pode ser resultado de uma supervisão rigorosa do BACEN.

Mesmo sem uma comprovação estatística significativa, acredita-se que em longo prazo as normas internacionais impactarão nos indicadores econômico-financeiros de instituições financeiras brasileiras, conforme a aderência do Banco Central do Brasil, já citada, e também por meio da constante adaptação das interpretações da nova normativa internacional. Concordou-se com a afirmação de Girbina et al. (2012), quando diz que já existem resultados positivos a serem observados no IFRS, tais como: melhor comparabilidade, transparência e confiança para o investidor.

Como sugestão de estudos futuros, recomenda-se examinar o impacto das normas internacionais em uma escala longitudinal (2010 a 2020) das instituições financeiras brasileiras, assim haverá maiores chances de identificação de diferenças relevantes entre os padrões contábeis. Também, sugere-se continuar essa pesquisa e verificar o impacto nos indicadores econômico-financeiros decorrentes de outras mudanças que ocorreram nos padrões contábeis.

\section{Referências}

Almeida, D. L. (2010). Reclassificação dos ativos financeiros e os possíveis impactos nos indicadores prudenciais e de rentabilidade dos bancos brasileiros. Dissertação de Mestrado, Faculdade de Economia, Administração e Contabilidade, Universidade de São Paulo, São Paulo. doi:

https://doi.org/10.11606/D.12.2010.tde-13102010-182733

Amrutha, P., Selvam, M., \& Kathiravan, C. (2019). Impact of Converging to IFRS on Key Financial Ratios with Reference to BSE Listed Firms. International Journal of Psychosocial Rehabilitation, 23(1). https://doi.org/10.37200/lJPR/V23I1/PR190263

Anjos, S. O. (2010). Abertura. Anais da Semana de Contabilidade do Banco Central do Brasil. Editora Bacen. Disponível em: http://www.bcb.gov.br/pre/evento/arquivos/2010 8 121/Sergio\%20Odilon.pdf. Acesso em: 18 nov. 2013.

Bueno, A. F., \& Lopes, E. (2005). Harmonização Global das Práticas Contábeis. Contabilidade Internacional. São Paulo. Módulo 2.

Calcado, E. D., Dantas, J. A., Niyama, J. K., \& Rodrigues, J. M. (2013). Indicadores Econômico-Financeiros dos Bancos Brasileiros: Impactos Associados aos Padrões Contábeis do IASB e do BCB 2013. Anais do 13ํㅡㄴ 
Congresso USP Controladoria e Finanças. Disponível em:

http://www.congressousp.fipecafi.org/web/artigos132013/150.pdf. Acesso em: 02 jun. 2013.

Calixto, L. (2010). Análise das Pesquisas com Foco nos Impactos da Adoção do IFRS em Países Europeus. Revista Contabilidade Vista \& Revista, 21(1):157-87.

Campbell, I. (2007). Chi-squared and Fisher-Irwin tests of two-by-two tables with small sample recommendations. Statistics in Medicine, 26(19):3661-75. https://doi.org/10.1002/sim.2832

Carvalho, L. N. (2009). Empresas ainda têm dúvida sobre qual o padrão seguir. In: International Financial Reporting Standards. Journal - Ernst \& Young, 8. Disponível em: http://www.ey.com.br/Publication/vwLUAssets/IFRS Journal 8/\$FILE/IFRS Journal 8.pdf. Acesso em: 18 nov. 2013.

Chiqueto, F. (2008). Impactos na provisão para devedores duvidosos dos bancos europeus listados na Bolsa de Nova lorque após a adoção das normas internacionais de contabilidade. Dissertação de Mestrado, Faculdade de Economia, Administração e Contabilidade, Universidade de São Paulo, São Paulo. doi: https://doi.org/10.11606/D.12.2009.tde-27032009-150621

Ernst \& Young. (2005). IFRS - the implications for European banks. London: Eygm Limited. Disponível em: http://www2.eycom.ch/publications/items/ifrs/single/200610 impact euro banks/200610 eyimpact ifrs euro banks.pdf. Acesso em: 18 nov. 2013

Farias, J. B., Ponte, V. M. R., Oliveira, M. C., \& Luca, M. M. M. (2014). Impactos da adoção das IFRS nas demonstrações contábeis consolidadas dos Bancos listados na BM \& FBovespa. Revista Universo Contábil, 10(2):63-83. DOI: https://doi.org/10.4270/RUC.2014212

Fé Júnior, A. L. D. (2013). Mudanças contábeis e reações do mercado na implantação compulsória do IFRS no setor bancário brasileiro. Dissertação de Mestrado, Faculdade de Economia, Administração e

Contabilidade de Ribeirão Preto, Universidade de São Paulo, Ribeirão Preto. doi:

https://doi.org/10.11606/D.96.2013.tde-22012014-170531

Gebhardt, G., \& Novotny-Farkas, Z. (2010). Mandatory IFRS Adoption and Accounting Quality of European Banks. SSRN. Disponível em: http://papers.ssrn.com/sol3/papers.cfm?abstract id=1732166. Acesso em: 14 out. 2013.

Girbina, M., Minu, M., Bunea, S., \& Sacarin, M. (2012). Perceptions of Preparers from Romanian Banks Regarding IFRS Application. Journal of Accounting and Management Information Systems, 11(2):191-208.

International Accounting Standards Board (IASB). (2011). IFRS - Normas Internacionais de Relatório Financeiro. IBRACON.

ludícibus, S. (2010). Teoria da Contabilidade. 10. ed. Editora Atlas.

Klan, R. C. (2007). Impacto das diferenças de Normas Contábeis Brasileiras, Americanas e Internacionais em Indicadores de Desempenho de Empresas. Dissertação de Mestrado, Universidade Regional de Blumenau, Blumenau, Brasil.

Klan, R. C., \& Beuren, I. M. (2011). Efeitos da Convergência Contábil às IFRS no Gerenciamento de Resultados de empresas Europeias. Anais V Congresso ANPCONT.. Disponível em: http://www.anpcont.com.br/site/docs/congressoV/CUE041.pdf. Acesso em: 07 ago. 2012.

Kraft, P., Landsman, W. R., \& Shan, Z. (2020). Effect of Mandatory IFRS Adoption on Accounting-Based Prediction Models for CDS Spreads. European Accounting Review. https://doi.org/10.1080/09638180.2020.1760116

Leventis, S., Dimitropoulos, P. E., \& Anandarajan, A. (2010). Loan Loss Provisions, Earnings Management and Capital Management under IFRS: The Case of EU Commercial Banks. Journal of Financial Services Research, 39. Disponível em: http://link.springer.com/article/10.1007\%2Fs10693-010-0096-1\#page-1. Acesso em: 18 nov. 2013.

Lopes, A. B., Galdi, F. C., \& Lima, I. S. (2011). Manual de contabilidade e tributação de instrumentos financeiros e derivativos: CPC 38, CPC 39, CPC 40, OCPC 3, IAS 39, IAS 32, IFRS 7, Normas da Comissão 
de Valores Mobiliários, do Banco Central do Brasil e da Receita Federal do Brasil. 2. ed. Editora Atlas.

Mackenzie, B., Coetsee, D., Njikizana, T., Chamboko, R., Colyvas, B., \& Hanekom, B. (2013). IFRS 2012: Introdução e Aplicação. Editora Bookman.

Miranda, V. L. (2008). Impacto da adoção das IFRS (Internacional Financial Reporting Standards) em indicadores econômico-financeiros de bancos de alguns países da União Europeia. Dissertação de Mestrado, Universidade de São Paulo, São Paulo, Brasil. https://doi.org/10.11606/D.12.2008.tde-14052008$\underline{125351}$

Neves, T. J. G., Lagioia, U. C. T., Libonati, J. J., Nascimento, S. G. O A. S., Marinho, R. F., Lemos, L. V. (2012). Utilidade dos Relatórios Contábeis após a Implantação das IFRS: Um Estudo Sobre a Visão dos Investidores. Anais do XXXVI Encontro da ANPAD. Disponível em:

http://www.anpad.org.br/evento.php?acao $=$ trabalho\&cod edicao subsecao $=848 \&$ cod evento edicao $=63 \& \mathrm{C}$ od edicao trabalho=14534. Acesso em: 06 ago. 2013.

Perez Junior, J. H. (2009). Conversão de demonstrações contábeis. 7. ed. Editora Atlas.

Pires, C. O., \& Decourt, R. F. (2015). The impacts of the final phase of transition to IFRS in Brazil. Revista Brasileira de Gestão e Negócios - FECAP, 17(54):736-50. https://doi.org/10.7819/rbgn.v17i54.1475

Sayed, S. (2012). O uso do valor justo e suas relações com os valores de mercado das instituições financeiras. Dissertação de Mestrado, Faculdade de Economia, Administração e Contabilidade, Universidade de São Paulo, São Paulo. doi: https://doi.org/10.11606/D.12.2013.tde-03052013-184847

Silveira, M. S. (2014). O Impacto da Adoção das IFRS na Variabilidade dos Índices Econômicos-Financeiros de Empresas Listadas na Bovespa. Dissertação de Mestrado, Universidade do Vale do Rio dos Sinos, São Leopoldo, Brasil.

Tombini, A. (2013). Discurso durante International Financial Reporting Standards. Banco Central do Brasil. Disponível em: http://www.bcb.gov.br/pec/appron/apres/Discurso\%20Tombini\%20IFRS.pdf. Acesso em: 18 nov. 2013.

Valério, L. H. (2011). Impacto da Adoção das IFRS (International Financial Reporting Standards) em Indicadores Econômico-Financeiros. Um Estudo de Caso Múltiplo em Empresas do Setor de Transporte Aéreo Listadas na Bolsa de Valores de São Paulo. Dissertação de Mestrado, Pontifícia Universidade Católica de São Paulo, São Paulo, Brasil.

\section{NOTAS}

\section{AGRADECIMENTOS}

Não se aplica.

\section{CONTRIBUIÇÃO DE AUTORIA}

Concepção e elaboração do manuscrito: T. Daneberg, R. F. Decourt

Coleta de dados: T. Daneberg

Análise de dados: T. Daneberg, R. F. Decourt

Discussão dos resultados: T. Daneberg, R. F. Decourt

Revisão e aprovação: T. Daneberg, R. F. Decourt

\section{CONJUNTO DE DADOS DE PESQUISA}

O conjunto de dados que dá suporte aos resultados deste estudo não está disponível publicamente.

\section{FINANCIAMENTO}

Não se aplica.

\section{CONSENTIMENTO DE USO DE IMAGEM}

Não se aplica.

\section{APROVAÇÃO DE COMITÊ DE ÉTICA EM PESQUISA}

Não se aplica. 


\section{CONFLITO DE INTERESSES}

Não se aplica.

\section{LICENÇA DE USO}

Os Direitos Autorais para artigos publicados neste periódico são do autor, com direitos de primeira publicação para a Revista. Em virtude de aparecerem nesta Revista de acesso público, os artigos são de uso gratuito, com atribuições próprias, em aplicações educacionais, de exercício profissional e para gestão pública. A Revista adotou a licença Creative Commons Atribuição 4.0 Internacional - CC BY NC ND. Esta licença permite acessar, baixar (download), copiar, imprimir, compartilhar, reutilizar e distribuir os artigos desde que com a citação da fonte, atribuindo os devidos créditos de autoria. Nesses casos, nenhuma permissão é necessária por parte dos autores ou dos editores. Autores têm autorização para assumir contratos adicionais separadamente, para distribuição não-exclusiva da versão do trabalho publicada nesta revista (ex.: publicar em repositório institucional ou um capítulo de livro).

\section{PUBLISHER}

Universidade Federal de Santa Catarina. Curso de Ciências Contábeis e Programa de Pós-graduação em Contabilidade. Publicação no Portal de Periódicos UFSC. As ideias expressadas neste artigo são de responsabilidade de seus autores, não representando, necessariamente, a opinião dos editores ou da universidade.

\section{EDITORES}

Carlos Eduardo Facin Lavarda e Suliani Rover

\section{HISTÓRICO}

Recebido em: 19/06/2019 - Revisado por pares em: 15/06/2020 - Reformulado em: 08/11/2020 Recomendado para publicação em: 09/11/2020 - Publicado em: 15/01/2021 